\title{
Subsidy Competition and the Mode of FDI*
}

\author{
Facundo Albornoz ${ }^{\dagger} \quad$ Gregory Corcos $^{\ddagger} \quad$ Toby Kendall ${ }^{\S}$
}

December 2008

\begin{abstract}
We model subsidy competition for a foreign MNC's investment in two trading partners. Taking into account acquisitions as an alternative investment mode weakens the case for subsidising greenfield investment. Competition between countries results in welfare losses, which are reinforced by positive externalities from the MNC's presence and regional integration. The results also apply to situations where the acquisition price accounts for the possibility of subsidies and when governments use acquisition subsidies as an alternative to greenfield subsidies.
\end{abstract}

JEL-Classification: F15, F21, F23

Key-words: Subsidy Competition, FDI, Greenfield Investment, Mergers and Acquisitions, Regional Integration, Positive Externalities

\section{Introduction}

The widespread use of investment incentives to influence MNC location, leading to 'subsidy wars', is now well documented (UNCTAD, 1996; Oman, 2000; Charlton, 2003). Subsidy wars have occurred in emerging and rich countries alike, particularly within regional blocs. Indeed, some of the most notable and fierce bidding contests have arisen in the European automobile and semi-conductor industries, while AFTA and Mercosur have been accompanied by increased

\footnotetext{
${ }^{*}$ We thank Ives Zenou, two anonymous referees, Thierry Mayer, Peter Neary, Thierry Verdier, seminar participants at ETSG 2005 (Dublin), EEA 2007 (Budapest), University of Birmingham and the Paris School of Economics.

${ }^{\dagger}$ Department of Economics, University of Birmingham, email f.albornoz@bham.ac.uk

${ }^{\ddagger}$ Department of Economics, Norwegian School of Economics and Business Administration, email gregory.corcos@nhh.no

${ }^{\S}$ Department of Economics, University of Birmingham, email t.kendall@bham.ac.uk
} 
competition for investment in South East Asia and South America respectively. ${ }^{1}$ At the same time, there has also been intense subsidy competition taking place within some large countries, most notably in Brazil, the US, Canada, India and China (see Oman, 2000 for examples).

Recent years have also seen an increase in FDI, with cross-border mergers and acquisitions increasing in importance relative to greenfield investment, accounting for a majority of new investment in developed countries. Calderón et al. (2002) report that merger and acquisition activity almost doubled as a percentage of GDP (and increased as a share of total investment) in industrialised countries between the late 1980s and the late 1990s. Over the same period in developing countries, while greenfield investment still accounted for a majority of FDI, mergers and acquisitions increased by more than nine times as a share of GDP, whereas the increase in total FDI inflows was approximately threefold.

In this paper, we study the welfare effects of subsidy competition for FDI. We model two trading partners that compete for the location of foreign firms by offering investment subsidies in a context where firms consider cross-border acquisitions as an alternative to greenfield investment. We show that this alternative worsens the expected welfare consequences of subsidy competition. Intuitively, in a world where governments compete for greenfield FDI, acquisition serves as an outside option for the investor. This outside option strengthens its bargaining position vis-a-vis the host country governments, resulting in a higher greenfield investment subsidy often sufficient to reduce regional welfare. Interestingly, this result carries over to the case where there are positive externalities from FDI such as job-creation effects. Therefore taking cross-border acquisitions into account can dramatically affect the welfare implications of subsidy competition for FDI.

A premise of our argument is that MNCs may consider greenfield FDI and mergers and acquisitions as substitutable alternative methods of investment. Indeed, there is no reason to

\footnotetext{
${ }^{1}$ European examples include competition leading to heavily subsidised car plants for BMW in Leipzig, Germany in 2001 and Nissan in Sunderland, UK in 2000, while in 2004, AMD was offered $\$ 550$ million to locate a microchip production facility in Dresden, Germany. In ASEAN, Thailand outbid the Philippines in 1996 to land a $\$ 500$ million investment from General Motors. More details on these and other examples are provided in the working paper version of this paper, while Oman (2000) and Charlton (2003) offer far more comprehensive discussion.
} 
think that an MNC would not choose the optimal mode of investment. It is a surprising feature of most of the literature on FDI that it exclusively considers either greenfield or mergers and acquisitions, as if the two were independent activities. In this sense, our paper complements a growing literature that investigates the investment choice in equilibrium (Mattoo et al., 2004, Bjorvatn, 2004, Bertrand, 2005).

Some authors have argued that subsidies can make investors internalise the wedge between social and private returns to FDI. With asymmetric externalities, subsidies may direct FDI to the location where its social return is higher, potentially reversing the location outcome and restoring allocative efficiency. ${ }^{2}$ In addition, subsidies can help governments trigger agglomeration even in an initially symmetric world, and capture part of the agglomeration rents enjoyed by foreign multinationals. ${ }^{3}$ We contribute to this literature by showing that the realistic assumption of acquisitions as an alternative mode of FDI reinforces the negative effects of subsidy competition even in the presence of positive externalities associated with greenfield investment.

We consider a region composed of a large and a small country. We model subsidy competition as a (second-price) auction where governments non-cooperatively offer lump-sum subsidies to an extra-regional investor. We initially assume that subsidies are only available to greenfield investors, in line with the observation that none of the 'landmark cases' mentioned in the UNCTAD and OECD-commissioned surveys involve mergers or acquisitions. To the best of our knowledge, investment incentives have only been granted to greenfield projects. This might be partly due to employment effects and other positive externalities associated with greenfield investment that are unlikely to accrue to the same extent with acquisitions. In addition, policy makers often view acquisitions of domestic firms by foreign predators as undesirable, fearing anti-competitive effects of increasingly concentrated ownership by large MNCs while ignoring the possible transfer of improved technology into a country, with potentially beneficial effects

\footnotetext{
${ }^{2}$ This argument has been made in the cases of employment effects (Barros and Cabral, 2000), technological spillovers (Fumagalli, 2003), increase in host-country competition (Bjorvatn and Eckel, 2006), or any other positive country-specific externality associated with MNC operations (Blomström and Kokko, 2003).

${ }^{3}$ See for example Kind et al. (2000), Ludema and Wooton (2000).
} 
for consumers in the region. ${ }^{4}$ One possible reason for this is that policy makers do not recognise that acquisitions involve payments to the original owners of the firm, which should compensate them for any lost future profits. We later extend the model to allow for acquisition subsidies and find that there are equilibria in which governments subsidise acquisitions and acquisition subsidy competition will arise with sufficiently high fixed costs of greenfield investment.

We show that subsidies allow the allocation of FDI to the large country, which is the efficient location as the costs of accessing both markets are minimised. ${ }^{5}$ However, subsidy competition also distorts the investment type towards greenfield FDI, with the large subsidies required often sufficient to reduce regional welfare. We identify cases where subsidy competition for greenfield investment reduces regional welfare when the alternative of acquisition is available. We show that subsidy competition will be harmful in a number of plausible cases, depending on the fixed costs associated with the investment project, and never beneficial. This is because competition leads to situations where greenfield FDI occurs in the efficient location, but regional welfare would be higher if the foreign firm entered through acquisition, which would be the outcome without subsidisation. An interesting implication for policy purposes is that welfare is greater under duopoly after the foreign acquisition than in a triopoly formed by subsidy competition.

As mentioned above, these results persist even in the presence of positive externalities such as employment effects. Indeed, we find that subsidy competition will be harmful for an even greater range of fixed costs. This is because the small country's social benefit from hosting the $\mathrm{MNC}$ is now greater relative to accepting an acquisition in the rival country. This forces the large country to subsidise the MNC in a greater range of cases. This result contrasts with the above-mentioned models where positive FDI externalities strengthen the case for subsidy competition.

\footnotetext{
${ }^{4}$ Although the positive effects of foreign acquisitions have not been clearly established by the literature, Arnold and Javorcik (2007) show how foreign acquisitions raised plant productivity in Indonesia. Kendall and Ryan (2006) consider the welfare and competition policy implications of international acquisitions. Acquisitions that involve the transfer of technology from a more efficient foreign predator to a domestic target are shown to be welfare-improving for the domestic country.

${ }^{5}$ Haaland and Wooton (1999) and Haufler and Wooton (1999) study tax competition for FDI in the presence of geographical advantages such as proximity to a large market or to a pool of suppliers or workers.
} 
We explore three extensions. First, falling trade costs; second, acquisition prices that react endogenously to subsidy offers, and third, subsidies to FDI by acquisition. In all these cases, the welfare-reducing effects of subsidy competition are reinforced.

The rest of this paper is set out as follows. Section 2 sets up the model. Section 3 characterises equilibria of the subsidy game between the two governments in the region. This allows us to first analyse welfare effects arising purely from changes to market structure and then allow for additional externality effects of FDI. Section 4 analyses the extensions of the model. Section 5 concludes.

\section{The model}

The world is assumed to consist of three countries, 1, 2 and 3. Countries 1 and 2 are potential partners in a preferential trade agreement (PTA) while 3 is a foreign country from outside the region. Each country contains a firm, indexed by country: firms 1 and 2 already sell in their own and each others' markets, while firm 3 can choose between greenfield investment and mergers and acquisitions to supply the markets in the two potential PTA partners. ${ }^{6}$ The foreign firm is assumed to have a lower marginal cost than the other two firms and can transfer this cost advantage to any plant it buys or establishes in another country. ${ }^{7}$

We consider a three-stage game. In the first stage the two partner governments set the levels of lump-sum location subsidies to the foreign firm, should it choose to invest in either partner country.

In the second stage, the foreign firm chooses how to supply the partner countries. It faces two choices (assuming at least one to be profitable): greenfield FDI, setting up a new plant in either country 1 or 2 ; or acquiring the existing firm in either country 1 or 2 . If it chooses greenfield FDI, it will face a fixed set-up cost and a trade cost for each unit shipped between

\footnotetext{
${ }^{6}$ In order to concentrate on the choice of investment mode, we rule out the possibility of exports from country 3. To reduce the number of cases that must be considered we also rule out the possibility of buying out both firms.

${ }^{7}$ Unlike Mattoo et al. (2004), we do not allow firms to choose the degree of technology transfer, instead we assume the full technological advantage is always transferred.
} 
countries 1 and 2. If it chooses acquisition, it will also pay this trade cost, plus an acquisition price whose formation is explained below.

In the third stage, all firms remaining in the market sell a homogeneous product under Cournot competition. Markets are segmented, meaning that we can ignore the market in country 3 when analysing the effects of regional integration on countries 1 and 2 . We note that, because of their lump-sum nature, subsidies and fixed costs do not affect third-stage production decisions, but only the second-stage investment decisions. ${ }^{8}$

Country $i$ 's demand curve is given by

$$
p_{i}=a_{i}-\sum_{j} q_{i j}
$$

where $p_{i}$ is the price in country $i(i=1,2)$ and $q_{i j}$ is firm $j(j=1,2,3)$ 's sales in country $i$. The $a_{i}$ parameters can be interpreted in various ways. The most literal interpretation is in terms of country sizes, with country 1 larger (smaller) than country 2 for $a_{1}>(<) a_{2}$. However these parameters could also be thought of as representing other factors, such as tastes, which result in differences in demand between countries.

Firm $j$ selling in country $i$ has a marginal cost of $c_{i j}$, which might consist of two components: a constant marginal cost of $c>0$ for $j=1,2$ or zero for $j=3$ and a trade cost, due to one or all of transport costs, tariffs or non-tariff barriers, of $\tau$ if production takes place outside country $i$.

The foreign firm (firm 3) has to pay a fixed cost of $F$ if it sets up a new plant in country 1 or 2 , but may receive a location subsidy of $S_{i}$ from government $i$ to locate there. ${ }^{9}$

Firm 3 can alternatively acquire either firm 1 or 2 and produce in that firm's country, transferring its cost advantage and thus producing with a marginal cost of zero.

As in most of the literature on mergers and acquisitions, we assume that the acquisition price is exogenously determined and given by the profits earned by the acquired firm prior to

\footnotetext{
${ }^{8}$ This implicitly assumes that firm 3 will continue to supply its own market from its original plant in country 3 rather than shutting that plant down and importing from a plant in country 1 or 2.

${ }^{9}$ This subsidy is constrained to be non-negative, so a lump-sum tax is not possible in this model. We make this assumption as our focus is on competing for investment.
} 
acquisition. ${ }^{10}$ The acquisition price for the firm in country 1 is given by:

$$
\text { AqPice }_{1}=\pi_{11}^{D}+\pi_{21}^{D}
$$

where $\pi_{11}^{D}=\left(\frac{a_{1}-c+\tau}{3}\right)^{2}$ and $\pi_{21}^{D}=\left(\frac{a_{2}-c-2 \tau}{3}\right)^{2}$ are firm 1's duopoly profits in countries 1 and 2 before entry by firm 3. A similar expression exists for the acquisition price of firm 2 .

In the final output stage, Stage 3, firm $j$ faces the following profit maximisation problem:

$$
\max _{q_{i j}} \Pi_{j}=\sum_{i} \pi_{i j}=\sum_{i}\left(p_{i}-c_{i j}\right) q_{i j}
$$

This is solved to find Cournot outputs and prices under four different modes of entry by firm 3. These are greenfield FDI and acquisitions in country 1 (denoted $G 1$ and $A 1$ respectively) or country 2 (G2 and A2). These outputs and prices are included in Appendix 1.

For each firm selling in each market, profits, net of any fixed costs, lump-sum subsidies or acquisition payments, are equal to $\pi_{i j}^{k}=\left(q_{i j}^{k}\right)^{2}$, for $k=\{G 1, A 1, G 2, A 2\}$. In the absence of government intervention, we derive the following condition for firm 3's profits from greenfield FDI to be greater than those from acquiring the domestic firm:

$$
\pi_{13}^{G 1}+\pi_{23}^{G 1}-F>\pi_{13}^{A 1}+\pi_{23}^{A 1}-\text { AqPrice }_{1}
$$

We now allow for the possibility of government intervention and define the welfare function for country $1 .{ }^{11}$ We assume that the government does not set an output tax/subsidy, but only a lump-sum subsidy. Additionally, in this section and Section 3, we assume that this subsidy is only ever given for greenfield investment; no acquisition will ever be subsidised, even if this would increase the country's welfare. ${ }^{12}$

\footnotetext{
${ }^{10}$ See for example Salant et al. (1983), Head and Ries (1997), Long and Vousden (1995) and Falvey (1998). We endogenise acquisition prices in Section 4.2.

${ }^{11}$ To avoid repetition, we do not define a welfare function for country 2 here, simply noting that it takes the obvious form. We amend the welfare functions in subsection 3.2 to allow for positive externalities.

${ }^{12}$ As noted in the introduction, investment subsidies are invariably observed to be given to greenfield projects rather than acquisitions. An additional reason for not initially considering the possibility of acquisition subsidies comes from our emphasis on subsidy competition for investment. The natural focus here is to concentrate on the
} 
The components of welfare differ according to the type of investment by the foreign firm but take the general form

$$
W_{1}^{k}=C S_{1}^{k}+\pi_{11}^{k}+\pi_{21}^{k}-S_{1}^{k}+A q P r i c e_{1}^{k}
$$

for $k=\{G 1, A 1, G 2, A 2\}$, where $C S_{1}^{k}=\left(Q_{1}^{k}\right)^{2} / 2$ gives consumer surplus with investment of type $k$. For all types of investment, $C S_{1}^{k}$ is strictly positive, but each of the other terms equals zero in at least one case. Unlike all other cases, $A 1$ involves firm 1 being acquired by firm 3 , hence $\pi_{11}^{A 1}=\pi_{21}^{A 1}=0$, while AqPrice ${ }_{1}^{k}=0$ for $k=\{G 1, G 2, A 2\}$. Only $G 1$ might involve an actual subsidy payment by government 1 , so that $S_{1}^{k}=0$ for $k=\{A 1, G 2, A 2\}$.

\section{Subsidy competition}

We now introduce two active governments, and solve for the equilibrium of the three-stage game described in the previous section.

\subsection{The lump-sum subsidy game}

Some useful notation Before we solve the game by backward induction we introduce some useful notation. $S_{1}$ and $S_{2}$ denote the subsidies simultaneously committed to by governments 1 and 2, respectively. ${ }^{13} \theta$ denotes the investment type (location and mode) belonging to $\{G 1, G 2, A 1, A 2\}$, as defined in Section 2.

We denote by $\Delta_{i i^{\prime}}^{k k^{\prime}}$ the difference between gross profits (excluding subsidies and fixed costs), in location $i$ using mode $k$ and profits in location $i^{\prime}$ using mode $k^{\prime}$, with $i, i^{\prime} \in\{1,2\}$ and $k, k^{\prime} \in\{A, G\}$. This allows us to compare the payoffs associated with each investment type

observed competition for new plants, rather than governments competing to have their local firms acquired. The latter is not observed, perhaps for political rather than economic reasons. In section 4.3 below, we analyse the model when acquisition subsidies are available to governments.

${ }^{13} \mathrm{We}$ assume credible commitments. In real economic situations, concerns for reputation towards future investors may arguably be enough to discipline governments. However, this remains beyond the scope of our single-investment model. 
more easily. As an illustration, the MNC prefers greenfield investment to an acquisition if $\Delta_{11}^{G A}>0$, which is a rearrangement of (4).

In an analogous way, we denote by $\chi_{i^{\prime} i^{\prime \prime}}^{k k^{\prime}}(i)$ the difference between gross welfare (excluding subsidies) in country $i$ with location $i^{\prime}$ and mode $k$, and welfare in country $i$ with location $i^{\prime \prime}$ and mode $k^{\prime}$. As an illustration, government 1 prefers acquisition at home to greenfield investment in country 2 if $\chi_{12}^{A G}(1)>0$.

Preliminary assumptions The equilibrium of such a subsidy game must depend on the location choice of the MNC in the absence of subsidisation. This, as in Haufler and Wooton (1999), will depend on the geographical advantage (home market size) enjoyed by one of the two countries. By convention, we suppose that country 1 is the large country and therefore hosts the MNC when subsidies are zero. ${ }^{14}$

A second assumption we must make is that the small country does not have too low a valuation of the MNC's presence to compete with its rival. This happens in particular when country 2 is too small relative to country 1 (or tastes are too different), or when the tariff is too high, implying a strong 'home market effect' to the detriment of country 2 . We assume that the following condition is met:

$$
\chi_{21}^{G G}(2)-\Delta_{12}^{G G}>0 \Longleftrightarrow \tau \frac{1}{32}\left(14 a_{2}-8 a_{1}-4 c-19 \tau\right)>0
$$

If this condition were not met, then no subsidy competition would take place and country 1 could even levy a tax on FDI. Since our objective is to analyse subsidy competition, we choose to rule out this degenerate case. As mentioned in the Introduction, subsidy competition is usually observed between similar and neighbour countries, which is consistent with our assumption.

\footnotetext{
${ }^{14}$ This simplifies the exposition, allowing us to avoid 'ties' in case of profit indifference. This amounts to labelling country 1 the country where the investment is more profitable. We later assume $a_{1}>a_{2}$, which implies this.
} 
Solving the model The solution to the three-stage game will be denoted by a triple $\left(S_{1}, S_{2}, \theta\right)$. We present a complete solution of the three-stage game in Appendix 2. We show there (Lemma 2) the existence and unicity of the subgame-perfect equilibrium of this game. We also show that this equilibrium must be of one of four different possible types, according to the parameters of the model and in particular the fixed cost of greenfield investment. We arrive at the following result, using $F_{1}$ and $F_{2}$ as defined in equation (27) in Appendix 2:

Proposition 1 The outcome of the subsidy game depends on the fixed costs of greenfield investment:

- $0 \leq F<\max \left\{F_{1}, F_{2}\right\}:\left(\chi_{21}^{G G}(2)-\Delta_{12}^{G G}, 0, G 1\right)$ (Equilibrium 1)

- $F \geq \max \left\{F_{1}, F_{2}\right\}:(0,0, A 1)$ (Equilibrium 2)

Proof. We defer to Appendix 2 the proofs of Lemmata 2 and 3 that predict which type of equilibrium prevails. Four candidate equilibria are defined in Lemma 2, only two of which are ever observed as actual equilibria. When $F<F_{M N C}$ we have Equilibrium $1{ }^{15}$ When $F_{M N C} \leq F<\min \left\{F_{1}, F_{2}\right\}$ we have Equilibrium 1 again. When $\min \left\{F_{1}, F_{2}\right\} \leq F<\max \left\{F_{1}, F_{2}\right\}$ government 2 prefers $A 1$ to $G 1$ but still can bid for $G 2$ so that we still obtain Equilibrium 1. Finally when $F>\max \left\{F_{1}, F_{2}\right\}$ no bid is possible and Equilibrium 2 obtains. ${ }^{16}$

In the case of low fixed costs, both governments value the MNC's presence enough to make a bid. ${ }^{17}$ However country 1 is able to outbid its rival thanks to its geographical advantage. By analogy to auctions, government 1 wins the bid by paying the second price. This value is equal to:

$$
\chi_{21}^{G G}(2)-\Delta_{12}^{G G}=\tau \frac{1}{32}\left(14 a_{2}-8 a_{1}-4 c-19 \tau\right)
$$

\footnotetext{
${ }^{15}$ Equilibrium 1 here is the same as Candidate Equilibrium 1 in Lemma 2.

${ }^{16}$ Equilibrium 2 here is the same as Candidate Equilibrium 4 in Lemma 2.

${ }^{17}$ Although the fixed costs do not directly enter the government's objective function, they do affect the level of subsidy required to attract the MNE. Hence lower fixed costs increase the likelihood that a government's valuation will be high enough for it to be willing to offer a subsidy.
} 
By Condition 1, this expression is positive.

For large enough fixed costs the equilibrium involves no intervention. In that case no government values greenfield investment at home enough, against the alternative of acquisition in country 1 , to incur any subsidy expenditure.

We now use this result to assess the welfare effects of subsidy competition. Whenever subsidy competition takes place in equilibrium, we measure regional welfare against the benchmark case of no intervention.

Implications for regional welfare Welfare implications of subsidy competition will similarly depend on the level of fixed costs for the greenfield investment project. We apply the results from Proposition 1.

In the case of low fixed costs $\left(0 \leq F<F_{M N C}\right)$ Equilibrium 1 always prevails. In other words, when both governments are able to bid for greenfield investment, government 1 always wins the auction. G1 obtains, as in the absence of intervention, but with positive subsidies which correspond to a welfare loss.

In the case of intermediate fixed costs $\left(F_{M N C} \leq F<\max \left\{F_{1}, F_{2}\right\}\right)$ Equilibrium 1 also prevails. Subsidy competition in Equilibrium 1 is socially harmful if regional welfare with $A 1$ and no subsidies is larger than welfare with $G 1$ and a subsidy equal to $\chi_{21}^{G G}(2)-\Delta_{21}^{G G}$, or formally:

$$
\chi_{11}^{G A}(1)-\left(\chi_{21}^{G G}(2)-\Delta_{21}^{G G}\right)+\chi_{11}^{G A}(2)<0 \Longleftrightarrow F_{1}-F_{2}^{\prime}+F_{2}-F_{2}^{\prime}<0
$$

where $F_{2}^{\prime}$ is as defined in equation (27).

Straightforward calculations using Equations (32) and (34) show that $F_{1}<F_{2}^{\prime}$ and $F_{2}<F_{2}^{\prime}$. Hence this difference is negative. Acquisition in country 1 without subsidies makes the region better off than greenfield investment in country 1 as the outcome of subsidy competition.

Finally, in the case of high fixed costs $\left(F>\max \left\{F_{1}, F_{2}\right\}\right)$ no intervention occurs. Then there is no scope for socially wasteful subsidy competition.

This proves the following result: 
Proposition 2 (Effects of subsidy competition on regional welfare) When subsidy competition occurs for greenfield FDI in the presence of an alternative choice of acquisition, it always reduces regional welfare. Its welfare evaluation depends on the fixed costs of greenfield investment:

- For low values of the fixed cost, such that greenfield investment is more profitable without subsidies, subsidy competition reduces social welfare relative to no intervention.

- For high values of the fixed cost, such that acquisition is the most profitable investment mode in the absence of subsidies, subsidy competition is harmful up to the level of fixed costs where both countries prefer an investment by acquisition in country 1 (the large country). Above that level of fixed costs no intervention occurs, hence there is no welfare loss.

This proposition states that putting an end to subsidy competition should enhance welfare in the region as a whole.

In particular, this is always true when fixed costs are low, in the sense that greenfield investment is relatively more profitable without any subsidies. In that case, the actions of both governments should affect neither the location nor the mode of investment $(G 1)$. Indeed country 1 hosts the MNC but it will need to pay government 2's willingness to subsidise. Subsidy expenditure is clearly a pure transfer of social surplus from the region to the multinational.

Higher fixed costs imply that the most profitable investment mode is acquisition. This should put a check on governments' ability to attract the MNC through subsidies, as they must now compensate for the profit differential between investment modes.

For intermediate values of the fixed costs, however, both governments are willing to subsidise the MNC. As in the low fixed costs case, government 1 wins the contest. Subsidy competition is still harmful as both governments prefer greenfield investment at home to greenfield investment abroad, even if one of them would favour an investment by acquisition.

Finally, when both countries prefer an investment by acquisition in country 1, there is logically no intervention. Therefore no welfare loss occurs. 
It should be noted again that we have assumed the absence of acquisition subsidies. This may be problematic where subsidy competition results in welfare-dominated greenfield investment. In that case a ban on investment subsidies would not automatically be justified; indeed, encouraging acquisition subsidies would perhaps be a cheaper means than a multilateral ban on greenfield subsidies, to distort the mode towards acquisitions. Therefore we add acquisition subsidies to our analysis in Section 4.3 below.

\subsection{The effects of positive externalities}

One important justification for granting subsidies to foreign direct investors has been the existence of positive externalities for the host country. ${ }^{18} \mathrm{MNC}$ activities may generate both horizontal (within-sector) and vertical (inter-sector) externalities that private investors fail to internalise in their decisions. Vertical spillovers from production might arise for a number of reasons, most notably due to employment effects or improved technological learning in a vertically linked sector. Horizontal spillovers are also plausible through imitation and increased competition.

In this section we bring the possibility of these and other positive externalities into the analysis. Empirical research on the field finds evidence of vertical FDI spillovers but it is less conclusive on the relevance of horizontal spillovers. ${ }^{19,20}$ Externalities are assumed to be proportional to the output of the foreign firm producing in 1 or 2 , and hence equal $\phi\left(q_{13}+q_{23}\right)$. They do not depend on the investment mode chosen by the MNC. While governments are assumed to recognise these unconditional externalities, we maintain the assumption of subsidies being conditional on greenfield investment. Our choice of modelling externalities as proportional to the MNC's output is designed to capture a range of possible externalities, rather than focussing solely on employment effects, as in Bjorvatn and Eckel (2006). To limit our analysis to em-

\footnotetext{
${ }^{18}$ See, for instance, Blomström and Kokko (2003).

${ }^{19}$ Aitken and Harrison (1999) find no evidence of horizontal spillovers in Venezuelan manufacturing. Blyde et al. (2004) replicate the same results for horizontal spillovers but find significant positive vertical spillovers. Kugler (2005) and Smarzynska Javorcik (2004) provide evidence of vertical spillovers taking place through contacts with local upstream suppliers

${ }^{20}$ For an analysis of the effects of subsidy competition for greenfield investment in the presence of horizontal spillovers, see Fumagalli (2003).
} 
ployment effects, we would need to make the externality term in equation (7) proportional to total output produced in country 1, rather than the MNC's output. This would further bias governments towards subsidising greenfield FDI, which would result in two firms producing in the country rather than one firm under acquisition, leading to higher employment in the country. Hence our analysis could arguably underestimate the potential scope for harmful subsidy competition.

The welfare function when firm 3 invests in country 1 now becomes:

$$
W_{1}^{k}=C S_{1}^{k}+\pi_{11}^{k}+\pi_{21}^{k}-S_{1}^{k}+\operatorname{AqPrice}_{1}^{k}+\phi\left(q_{13}^{k}+q_{23}^{k}\right)
$$

for $k=\{G 1, A 1\}$, with $\pi_{11}^{A 1}=\pi_{21}^{A 1}=S_{1}^{A 1}=$ AqPrice ${ }_{1}^{G 1}=0$.

Using this augmented welfare function, we can predict the outcome of the subsidy game.This is done in exactly the same way as in the previous subsection. With respect to our previous results, a qualitative change only occurs beyond a certain extent of externalities. We defer the characterisation of the prevailing equilibrium beyond the relevant amount of significant externalities to Lemma 4 in Appendix 3.

Let us now comment on the difference to our previous characterisation. When externalities are sufficiently high, government 2 has a stronger incentive to enter subsidy competition when acquisition would otherwise occur. Hosting the MNC now becomes socially more valuable compared to the alternative of acquisition abroad, which previously proved beneficial to local firms.

Proposition 3 Consider the existence of sufficiently high positive externalities in the sense of Lemma 4:

- The welfare effects of subsidy competition depend on the fixed costs of greenfield investment as follows:

- If fixed costs are low, in the sense that greenfield investment is more profitable, then subsidy competition reduces social welfare compared to no intervention. 
- If fixed costs are higher, but not high enough to make both governments prefer investment by acquisition, subsidy competition reduces social welfare compared to no intervention.

- With higher fixed costs no intervention, and hence no welfare loss, ever occurs.

- The range of fixed costs for which a welfare loss occurs is greater than in the absence of positive externalities, while subsidy expenditure is also greater.

Proof. See Appendix 3.

It can be seen that allowing for positive externalities strengthens our earlier results. While such externalities are often used by governments to justify subsidising investment, they actually increase the scope for harmful subsidy competition. The increase in the range of $F$ for which subsidy competition occurs is a direct result of externalities making investment more desirable to both countries, consequently increasing their willingness to subsidise it. Hence we find that, even though FDI is now more beneficial to residents of the host country, subsidy competition is still harmful. Again, the winner of this competition would also host the MNC without such competition. The intuition behind this seemingly identical result is slightly different, however.

Our main result can be interpreted as the outcome of a second-price auction. Governments' valuations depend on their welfare comparisons of greenfield investment at home and acquisition in country 1. No competition will take place when both governments value an acquisition in country 1 more highly than greenfield investment at home (taking into account the potentially large subsidies necessary to induce that location).

From the viewpoint of country 2 , an acquisition in country 1 reduces competition relative to greenfield investment, which benefits producers and harms consumers. The effect on consumers drives country 2's motivation to offer an investment subsidy when the fixed cost of investment is not too high. In most cases country 1 will generally be willing to bid for greenfield investment even for high values of the fixed cost, leading to both countries bidding for greenfield investment 
and a second-price auction result.

In the presence of positive externalities, country 2's willingness to subsidise can be significantly increased as these externality effects are lost in the event of an acquisition in country 1. When positive externalities are large enough, country 2 can be expected to be willing to bid even for high values of the fixed cost. However, country 1's geographical advantage allows it to always win the second-price auction. This implies a welfare loss by the same logic as in the previous subsection.

It should be noted that MNC output is higher under greenfield investment which implies a larger social value of positive externalities, as this value rises in proportion to MNC output. Greenfield investment should therefore be relatively more valuable to the host government, compared to the previous case. In other words, the competition motive and the externality motive for attracting FDI reinforce each other. ${ }^{21}$

\section{Extensions}

We now consider three extensions to our model. First, we consider the effects of trade integration, modelled as a reduction in trade costs between countries 1 and 2. Second, we allow acquisition prices to vary endogenously with subsidy offers. Third, we introduce the possibility of subsidising acquisitions as well as greenfield investment.

\subsection{The effects of trade integration}

We are interested in how freer trade between countries 1 and 2 modifies the effects of subsidy competition. Reductions in trade costs affect profits and welfare in a number of ways. This in turn changes the incentives to compete for MNC location and the costs associated with subsidy competition.

\footnotetext{
${ }^{21}$ An extension of this section with asymmetric valuations of externalities ( $\phi$ 's) would be straightforward. An interesting result is that a high enough valuation of externalities for country 2 could overturn the location outcome, offsetting the effect of country 1's geographical advantage. Obviously, the stronger the advantage, the larger the required difference in social valuations. Hence the claim that subsidies act as a signal of externalities rests on very particular conditions.
} 
We note first that the existence of subsidy competition requires a certain level of trade integration. From Condition 1 we can see that subsidy competition requires ${ }^{22}$

$$
0 \leq \tau<\frac{1}{19}\left[14 a_{2}-8 a_{1}-4 c\right]
$$

Therefore, if trade barriers were initially above this threshold level (which is positive from Condition 1), trade integration that reduced $\tau$ below this level would definitely trigger wasteful subsidy competition. We still need to see whether deeper trade integration mitigates or exacerbates the negative effects of subsidy competition.

We note that according to equation (28) in Appendix 2, the thresholds that determine the existence of Equilibrium 1 depend on $\tau$. Therefore, whether subsidy competition is less or more likely as trade integration proceeds depends on

$$
\frac{\partial F_{1}}{\partial \tau}=\frac{1}{144}\left(9 a_{1}-8 a_{2}+34 c+13 \tau+2 \phi\right)
$$

and

$$
\frac{\partial F_{2}}{\partial \tau}=\frac{1}{144}\left(9 a_{2}-8 a_{1}+2 c+13 \tau-36 \phi\right)
$$

When countries are very different in size, costs are high and positive externalities are low, the relevant threshold is $F_{1}$ (see the proof of Lemma 3 ). Remembering that $a_{1}>a_{2}$, this condition is always positive, hence trade integration reduces the scope of investment projects that result in subsidy competition.

In the presence of large positive externalities, when countries are sufficiently similar and when local firms' production costs are low enough, $F_{2}$ becomes the relevant condition. Its derivative with respect to $\tau$ will definitely be negative for sufficiently high positive externalities, meaning

\footnotetext{
${ }^{22}$ This condition is sufficient but not necessary. In the presence of positive externalities $(\phi>0)$ subsidy competition would occur with even greater tariffs. This is because country 2's willingness to pay is increasing with $\phi$, as can be seen from equation (44) in Appendix 3.
} 
that trade integration will increase the scope for subsidy competition. ${ }^{23}$

Trade integration also affects the level of subsidies offered to the MNC. From Equation (44) in Appendix 3 we have:

$$
\frac{\partial\left(\chi_{21}^{G G}(2)-\Delta_{12}^{G G}\right)}{\partial \tau}=\frac{1}{16}\left(7 a_{2}-4 a_{1}-2 c-4 \phi-19 \tau\right)
$$

which requires $a_{1}<\frac{7}{4} a_{2}-\frac{1}{2} c-\frac{19}{4} \tau-\phi$ to be positive. We observe that this is always satisfied by Condition 1 in the absence of (or with sufficiently low) positive externalities. Therefore, further trade integration reduces the cost of subsidy competition. The intuition behind this comes from the fact that, in the absence of externalities, the incentive to subsidise the foreign firm derives from gains to consumer surplus that result from its investment. ${ }^{24}$ Trade integration reduces the gain in country 1's consumer surplus from having the firm locate in that country, rather than country 2 , as the firm located abroad will incur lower transport costs and consequently supply a higher quantity to country 1 . Hence trade integration reduces country 1's incentive to subsidise investment, and a similar argument applies to country 2. Once we allow for sufficiently large positive externalities, this result is reversed for the following reason. The externalities provide a direct incentive for each country to subsidise investment and capture their benefits. As the externalities are proportional to the MNC's output, and as trade integration increases the MNC's total output due to the reduction in trade costs, trade integration increases the incentive for either country to subsidise investment. This leads to more intense subsidy competition and higher social waste.

The following Proposition summarises these results:

Proposition 4 Initial trade integration triggers subsidy competition. Increasing trade integration reduces the scope of regionally inefficient subsidy competition for low levels of positive

\footnotetext{
${ }^{23}$ This derivative could be positive when countries are of similar sizes and externalities less high, but we note that $F_{2}$ is only the relevant threshold for high positive externalities.

${ }^{24}$ The profits of firm 1 will be higher with greenfield investment in country 2 rather than 1 , while the payment firm 1 receives when acquired is also higher than its profits under greenfield investment. Hence, in the absence of positive externalities, the only possible incentive for country 1 wanting to attract greenfield investment derives from consumer surplus.
} 
externalities, sufficiently different country sizes and high production costs. Otherwise, further trade integration makes subsidy competition more likely. Deepening trade integration reduces the cost of subsidy competition when positive externalities are absent or low, but increases the cost of subsidy competition for sufficiently high positive externalities.

\subsection{Endogenous Acquisition Prices}

In this extension we look at the impact of subsidies on acquisition prices. Governments' commitment to subsidies influences the MNC's valuation of domestic targets. This affects the welfare analysis since acquisition prices are an important component of national welfare.

The acquisition process We follow Norbäck and Persson (2008) in modelling the acquisition process as an auction. ${ }^{25}$ The two domestic firms, 1 and 2, post selling bids to the multinational. The MNC may either accept one of the bids or enter by greenfield investment. Norbäck and Persson (2008) show that the outcome of the auction depends on the ranking between three valuations: that of the acquirer $\left(v_{m}\right)$, the reservation price of the target when the other target is acquired $\left(v_{d m}\right)$, and the reservation price of the target when the MNC chooses greenfield investment instead $\left(v_{d d}\right)$.

In this extension we assume that countries are symmetric, namely $a_{1}=a_{2}=a$. That way there are only 6 possible rankings of the 3 different valuations (since $3 !=6$, while there are $6 !=720$ permutations of 6 valuations). When profits are the same in both locations, each country can host the MNC with probability $\frac{1}{2}$. Using symmetry we only consider G1 and A1.

$$
\begin{aligned}
v_{d d} & \equiv \pi_{11}^{G 1}+\pi_{21}^{G 1}=\left(\frac{a-2 c+\tau}{4}\right)^{2}+\left(\frac{a-2 c-2 \tau}{4}\right)^{2} \\
v_{d m} & \equiv \pi_{11}^{A 2}+\pi_{21}^{A 2}=\left(\frac{a-2 c+\tau}{3}\right)^{2}+\left(\frac{a-2 c-2 \tau}{3}\right)^{2} \\
v_{m}\left(S_{1}, S_{2}\right) & \equiv\left(\pi_{13}^{A 1}+\pi_{23}^{A 1}\right)-\max \left\{\left(\pi_{13}^{G 1}+\pi_{23}^{G 1}\right)+S_{1}-F ;\left(\pi_{13}^{G 1}+\pi_{23}^{G 1}\right)+S_{2}-F\right\}
\end{aligned}
$$

\footnotetext{
${ }^{25}$ In particular we follow the logic of their section 5.2., which addresses competition among targets rather than competition among acquirers.
} 
$v_{m}\left(S_{1}, S_{2}\right)$ is the only valuation that depends on $F$. We define $F_{N C}$ as the value of $F$ that equalises $v_{m}(0,0)$ and $v_{d d}$, and $F_{C}$ as the value of $F$ that equalises $v_{m}(0,0)$ and $v_{d m}$.

$$
\begin{gathered}
F_{N C}=\left(\pi_{11}^{G 1}+\pi_{21}^{G 1}\right)+\left(\pi_{13}^{G 1}+\pi_{23}^{G 1}\right)-\left(\pi_{13}^{A 1}+\pi_{23}^{A 1}\right) \\
F_{C}=\left(\pi_{11}^{A 2}+\pi_{21}^{A 2}\right)+\left(\pi_{13}^{G 1}+\pi_{23}^{G 1}\right)-\left(\pi_{13}^{A 1}+\pi_{23}^{A 1}\right)
\end{gathered}
$$

Note that Cournot triopoly profits $v_{d d}$ are lower than duopoly profits $v_{d m}$, implying $F_{N C}<F_{C}$.

We start by describing the outcome of the acquisition bidding game as a function of the fixed investment cost in the absence of subsidies:

Lemma 1 In the absence of subsidies the outcome of the acquisition game is as follows. For low fixed costs, $F<F_{N C}$, no acquisition occurs and the foreign firm enters through greenfield investment. For intermediate fixed costs, $F_{N C} \leq F<F_{C}$, the MNC acquires firm 1 at price $v_{m}\left(S_{1}, S_{2}\right)$. For high fixed costs, $F \geq F_{C}$ the $M N C$ acquires firm 1 at price $v_{d m}$.

Proof. The proof follows directly from Proposition 4, section 5.2, and Appendix A.3 in Norbäck and Persson (2008).

Intuitively, at low fixed costs the MNC's valuation is too low relative to greenfield investment profits for acquisition to occur. When fixed costs are intermediate the MNC accepts the target's bid but firm 2 does not compete (subscript NC): its profit as a duopolist is higher than the MNC's willingness to pay (the 'merger paradox'). Finally when fixed costs are high enough, both target firms compete (subscript C). Competition drives down the acquisition price to the target's reservation price.

The augmented game We now consider a subsidy competition game with endogenous acquisition prices. In the first stage governments set subsidy levels as before. In the second stage the MNC can either enter by greenfield investment or accept one of the two targets' selling bids, taking subsidies as given and credible. In the third stage firms compete in Cournot fashion. 
The game is solved by backward induction. Third-stage outputs and gross profits are still as in Appendix 1 with $a_{1}=a_{2}$.

The second-stage subgame is solved as in Norbäck and Persson (2008, Appendix A3). Since only $v_{m}\left(S_{1}, S_{2}\right)$ depends on subsidies it is possible to give a unique ranking of valuations for each subsidy pair. There is a correspondence between the type of FDI (mode and location) and each subsidy pair. From Lemma 1 and Equations (11)-(15) we obtain:

$$
\theta= \begin{cases}G 1 & \text { if } \max \left\{S_{1}, S_{2}\right\}>F-F_{N C} \text { and } S_{1}>S_{2} \\ G 2 & \text { if } \max \left\{S_{1}, S_{2}\right\}>F-F_{N C} \text { and } S_{1}<S_{2} \\ G & \text { if } \max \left\{S_{1}, S_{2}\right\}>F-F_{N C} \text { and } S_{1}=S_{2} \\ A \text { at price } v_{m}\left(S_{1}, S_{2}\right) & \text { if } F-F_{C}<\max \left\{S_{1}, S_{2}\right\} \leq F-F_{N C} \\ A \text { at price } v_{d m} & \text { if } \max \left\{S_{1}, S_{2}\right\} \leq F-F_{C}\end{cases}
$$

where $G$ and $A$ denote the choice of greenfield investment and acquisition, respectively, when each country has a $\frac{1}{2}$ probability to host the MNC's investment.

In the first stage governments set their subsidies simultaneously to maximise welfare. Because best-replies are symmetric they must actually consider expected welfare in a lottery where they have a $\frac{1}{2}$ probability of hosting FDI. Denote by $\chi^{*}\left(S_{1}, S_{2}\right), \chi^{* *}$ the difference in welfare between the greenfield FDI "lottery" and, first, the acquisition "lottery" with price $v_{m}$, second, the acquisition "lottery" with price $v_{d m}$. Denote by $\chi^{* * *}$ the difference in welfare between hosting greenfield FDI with certainty and the other country hosting greenfield FDI with certainty.

By (16) the sign of $F-F_{N C}$ matters for the acquisition price, since subsidies are always positive. If $F-F_{N C}<0$ greenfield investment always occurs. Governments bid up to their willingness to subsidise $\chi^{* * *}$. If $F-F_{N C} \geq 0$ acquisitions are possible provided governments choose low subsidies. Governments' choices, in turn, are strategic. Facing a subsidy lower than $F-F_{N C}$, they can either obtain greenfield investment by offering $F-F_{N C}$ or refuse to subsidise and expect acquisition. Facing a subsidy greater than $F-F_{N C}$, they will again bid up to $\chi^{* * *}$. 
Country 1's best reply is given by:

$$
S_{1}^{B R}\left(S_{2}\right)= \begin{cases}\min \left\{S_{2}+\epsilon, \chi^{* * *}\right\} & \text { if } S_{2} \geq F-F_{N C}>F-F_{C} \\ 0 & \text { if } 0 \leq F-F_{C} \leq S_{2}<F-F_{N C} \text { and } \chi^{*}\left(S_{1}, S_{2}\right)<F-F_{N C} \\ F-F_{N C} & \text { if } 0 \leq F-F_{C} \leq S_{2}<F-F_{N C} \text { and } \chi^{*}\left(S_{1}, S_{2}\right) \geq F-F_{N C} \\ 0 & \text { if } 0 \leq S_{2}<F-F_{C} \text { and } \chi^{* *}<F-F_{N C} \\ F-F_{N C} & \text { if } 0 \leq S_{2}<F-F_{C} \text { and } \chi^{* *} \geq F-F_{N C}\end{cases}
$$

By symmetry, best-reply subsidies from government 2 are obtained in a similar way.

Straightforward calculations show that $\chi^{* *}<0$ and $\chi^{* * *}>0$. There are therefore two possible equilibria: $(0,0, \mathrm{~A})$ and $\left(\chi^{* * *}, \chi^{* * *}, \mathrm{G}\right)$, depending on the value of the fixed cost parameter:

Proposition 5 The outcome of the subsidy game depends on the fixed costs of greenfield investment:

- $0 \leq F \leq \min \left\{F_{N C}+\chi^{*}, F_{C}\right\}:\left(\chi^{* * *}, \chi^{* * *}, G\right)$

- $F>\min \left\{F_{N C}+\chi^{*}, F_{C}\right\}:(0,0, A)$

Proof. When $F \leq F_{N C}$ the acquisition price falls short of the reservation value of the target, so that there is greenfield investment and the $\left(\chi^{* * *}, \chi^{* * *}, \mathrm{G}\right)$ equilibrium. When $F_{C} \geq F>F_{N C}$ the equilibrium depends on $F$. It is in a government's interest to subsidise and obtain greenfield investment if and only if $\chi^{*}(0,0)>F-F_{N C} \Leftrightarrow F<\chi^{*}(0,0)+F_{N C}$. When $F>F_{C}$ the equilibrium is always $(0,0, \mathrm{~A})$ because $\chi^{* *}<0$, implying that it is always desirable to allow an acquisition to occur.

Welfare analysis How does the augmented subsidy game compare against the no intervention benchmark? Absent intervention (as in Lemma 1) there are three fixed cost intervals to consider. First, when $F \in\left[0, F_{N C}\right]$ greenfield investment is the outcome irrespective of intervention. The welfare loss is equal to the subsidies transferred to the MNC: $\chi^{* * *}$. Second, when 
$F \in\left[F_{N C}, \min \left\{F_{C}, F_{N C}+\chi^{*}(0,0)\right\}\right]$ the MNC chooses greenfield investment with subsidies and acquisition without. There is a welfare loss both from the mode distortion (equal to $\chi^{*}\left(\chi^{* * *}, \chi^{* * *}\right)$ for low fixed costs and $\chi^{* *}$ for high fixed costs) as well as a loss from subsidy expenditure $\chi^{* * *}$. Finally when $F \in\left[\min \left\{F_{C} ; F_{N C}+\chi^{*}(0,0)\right\} ;+\infty\right]$ there is no change.

Finally since each country is equally likely to host the FDI, global welfare is equal to twice each country's welfare. We thus have proved the following proposition:

Proposition 6 Subsidy competition with endogenous acquisition prices reduces welfare compared to no intervention if $F \leq \min \left\{F_{C}, F_{N C}+\chi^{*}(0,0)\right\}$, and does not increase welfare when fixed costs are higher.

As in the previous section, subsidy competition reduces welfare because of a distortion in the mode of FDI and a transfer to the foreign multinational. While governments' committing to subsidies can manipulate the acquisition price, they can only reduce the MNC's willingness to pay for an acquisition, which is not in their interest. While subsidised greenfield investment occurs now for a slightly different range of fixed costs, the results are qualitatively similar.

\subsection{Acquisition Subsidies}

We have shown that greenfield-subsidy competition may lead to efficiency and welfare losses. However, up to now we have not allowed for the possibility that governments may subsidise acquisition as well. Although we noted earlier that such subsidies are not generally observed, by allowing for the possibility of acquisition subsidies we can investigate whether their absence is an equilibrium outcome when governments have this policy instrument available to them, or due to other, most likely political, considerations. In what follows, we take the equilibrium greenfield subsidies in the previous section as given and allow for acquisition subsidies to be

offered by countries 1 and 2 , denoted by $S_{1}^{A}$ and $S_{2}^{A}$ respectively. This can be seen as a test of the robustness of our previous results. 
Low fixed costs For $F \in\left(0, \max \left\{F_{1}, F_{2}\right\}\right)$, no unsubsidised acquisition is possible in equilibrium, so with only greenfield subsidies Equilibrium 1 prevailed. However acquisition subsidy competition may take place when welfare gains from inducing acquisition are greater than the subsidy that would make the MNC prefer acquisition to greenfield with greenfield subsidies. Therefore the acquisition subsidy has to be greater that the difference between greenfield profits with subsidy and acquisition profits. That is for country $i$,

$$
\Delta^{S}(i)=\Delta_{1 i}^{G A}-F+S_{1}^{*}
$$

Hence with acquisition subsidies there is a possibility of A1 (A2) if $\chi_{11}^{A G}(1)>\Delta^{S}(1)\left(\chi_{21}^{A G}(2)>\right.$ $\left.\Delta^{S}(2)\right)$. From (18) this translates into conditions on fixed costs. We define $F_{A 1}$ and $F_{A 2}$ as the fixed costs such that these conditions hold with equality.

For $F \in\left(0, \min \left\{F_{A 1}, F_{A 2}\right\}\right)$ neither country subsidises acquisition and Equilibrium 1 prevails.

For $F \in\left(F_{A 1}, F_{A 2}\right)$, at least one country wishes to subsidise acquisition. Within this range, we know that country 1 is willing to subsidise acquisition when $F_{A 1}<F_{A 2}$, or equivalently when

$$
\left(\Delta_{11}^{G A}-\Delta_{12}^{G A}\right)-\left(\chi_{11}^{A G}(1)-\chi_{21}^{A G}(2)\right)<0
$$

and country 2 is willing to subsidise acquisition otherwise. The ranking of $F_{A 1}$ and $F_{A 2}$ is independent of $F$, with $F_{A 1}$ being larger for sufficiently high values of $a_{1}$ relative to $c$. As we cannot in general sign this condition, we consider the two possible cases separately:

$F_{A 1}<F<F_{A 2}$ : Country 1 is willing to pay at least $\Delta^{S}(1)$, which will induce the MNC to switch from greenfield to acquisition. Although country 2 would be unwilling to offer a subsidy to prevent G1, it would be willing to offer a subsidy to promote A2 over A1 if

$$
\chi_{21}^{A A}(2)>\chi_{11}^{A G}(1)+\Delta_{12}^{A A}
$$

This condition is satisfied for some values of $c$ when $a_{2}$ is small relative to $a_{1}$ (but within the range allowed by Condition 1 in Section 3.1), in which case country 1 would still be willing to 
outbid country 2 if

$$
\chi_{12}^{A A}(1)>\chi_{21}^{A A}(2)-\Delta_{12}^{A A}
$$

Straightforward calculations show that the two sides of equation (20) are equal. So the equilibrium is subsidised A1, with the government paying a subsidy of $\Delta^{S}(1)$, if condition (19) holds, or either $\mathrm{A} 1$ or $\mathrm{A} 2$, with the winning country paying its maximum willingness to pay $\chi_{12}^{A A}(1)$ or $\chi_{21}^{A A}(2)$, otherwise. ${ }^{26}$ We refer to the first type of equilibrium, where the government pays the minimum subsidy necessary to induce the MNC to acquire the firm in that country, as 'uncontested' and the second type, where the two countries compete in acquisition subsidies, as 'contested'.

$F_{A 2}<F<F_{A 1}$ : Country 2 is willing to pay at least $\Delta^{S}(2)$, which will induce the MNC to switch from greenfield in 1 to acquisition in 2. Although country 1 would be unwilling to offer a subsidy to induce A1 over G1, it would be willing to offer a subsidy to promote A1 over A2 if

$$
\chi_{12}^{A A}(1)>\chi_{21}^{A G}(2)-\Delta_{12}^{A A}
$$

This condition is never satisfied satisfied for $a_{1}>a_{2}$, so the equilibrium is uncontested subsidised $\mathrm{A} 2$.

For $F \geq \max \left\{F_{A 1}, F_{A 2}\right\}$, the two countries will compete for acquisition. The best-reply subsidy schedules are given by:

\footnotetext{
${ }^{26}$ That the government's willingness to pay is equal in each country is an artefact of our assumptions on linear demand and costs and identical technologies. As our main interest is in the existence of acquisition subsidy competition and its implications for regional welfare, rather than predicting which country will host the acquiring MNC, we choose not to make an arbitrary assumption as to whether A1 or A2 prevails. However, a natural tie-breaking rule might be that country 1, where the MNC would invest in the absence of subsidies, will be the location unless country 2 pays enough to make the MNC strictly prefer locating there. This would lead to A1 in this case and others below where the firm is indifferent between locations.
} 


$$
\begin{aligned}
& S_{1}^{A *}\left(S_{2}^{A}\right)= \begin{cases}\Delta^{S}(1) & \text { if } 0 \leq S_{2}^{A}<\Delta^{S}(2) \\
S_{2}^{A}-\Delta_{12}^{A A}+\epsilon & \text { if } \Delta^{S}(2) \leq S_{2}^{A}<\chi_{12}^{A A}(1)+\Delta_{12}^{A A} \\
0 & \text { if } S_{2}^{A} \geq \chi_{12}^{A A}(1)+\Delta_{12}^{A A}\end{cases} \\
& S_{2}^{A *}\left(S_{2}^{A}\right)= \begin{cases}\Delta^{S}(2) & \text { if } 0 \leq S_{1}^{A}<\Delta^{S}(1) \\
S_{1}^{A}+\Delta_{12}^{A A}+\epsilon & \text { if } \Delta^{S}(1) \leq S_{1}^{A}<\chi_{21}^{A A}(2)-\Delta_{12}^{A A} \\
0 & \text { if } S_{1}^{A} \geq \chi_{21}^{A A}(2)-\Delta_{12}^{A A}\end{cases}
\end{aligned}
$$

To see which country wins the acquisition-subsidy bidding war, we must compare their maximum willingness to pay, net of the difference between the MNC's profits from locating in the two countries, which we find to be equal. Therefore we have contested subsidised acquisition, with the country that attracts the MNC paying its maximum willingness to pay and subsidy competition will raise the level of subsidy paid and reduce welfare for the winning country.

High fixed costs $\left(F>\max \left\{F_{1}, F_{2}\right\}\right)$. For $F>\max \left\{F_{1}, F_{2}\right\}$, the equilibrium will always involve acquisition, even in the absence of subsidies. If no subsidy is offered, the MNC will acquire the firm in country 1 . Hence subsidies will be offered if country 2 is willing to pay a subsidy, which requires $\chi_{21}^{A A}(2)>\Delta_{12}^{A A}$. This condition always holds, so the best-reply subsidy schedules are given by:

$$
\begin{aligned}
& S_{1}^{A *}\left(S_{2}^{A}\right)= \begin{cases}S_{2}^{A}-\Delta_{12}^{A A}+\epsilon & \text { if } S_{2}^{A}<\chi_{12}^{A A}(1)+\Delta_{12}^{A A} \\
0 & \text { if } S_{2} \geq \chi_{12}^{A A}(1)+\Delta_{12}^{A A}\end{cases} \\
& S_{2}^{A *}\left(S_{1}\right)= \begin{cases}S_{1}^{A}+\Delta_{12}^{A A}+\epsilon & \text { if } S_{1}^{A}<\chi_{21}^{A A}(2)-\Delta_{12}^{A A} \\
0 & \text { if } S_{1}^{A} \geq \chi_{21}^{A A}(2)-\Delta_{12}^{A A}\end{cases}
\end{aligned}
$$


We must again compare the two countries' maximum willingness to pay, net of the difference between the MNC's profits from locating in the two countries, which we find to be equal. Therefore again the country that attracts the MNC will pay its maximum willingness to pay. Subsidy competition will raise the subsidy paid and reduce welfare for the winning country.

We summarise the above results as follows:

Proposition 7 With acquisition subsidies the equilibrium of the subsidy game is given by

- $F \in\left(0, \max \left\{F_{1}, F_{2}\right\}\right)$

$-F \in\left(0, \min \left\{F_{A 1}, F_{A 2}\right\}\right):\left(\chi_{21}^{G G}(2)-\Delta_{12}^{G G}, 0, G 1\right)$

- $F_{A 1}<F<F_{A 2}:\left(\Delta^{S}(1), 0, A 1\right)$ (uncontested) if condition (19) holds, otherwise $\left(\chi_{12}^{A A}(1), 0, A 1\right)$ or $\left(0, \chi_{21}^{A A}(2), A 2\right)$ (contested)

$-F_{A 2}<F<F_{A 1}:\left(0, \Delta^{S}(2), A 2\right)$ (uncontested)

- $F \geq \max \left\{F_{A 1}, F_{A 2}\right\}:\left(\chi_{12}^{A A}(1), 0, A 1\right)$ or $\left(0, \chi_{21}^{A A}(2), A 2\right)$ (contested)

- $F>\max \left\{F_{1}, F_{2}\right\}:\left(\chi_{12}^{A A}(1), 0, A 1\right)$ or $\left(0, \chi_{21}^{A A}(2), A 2\right)$ (contested)

The results of this section show that acquisition subsidies can occur in equilibrium for a wide range of fixed costs. Hence the fact that they are rarely, if ever, observed suggests that other factors influence governments' decisions. It is possible that policy-makers fail to recognise the payments made by foreign MNCs to domestic firms in compensation for loss of future profits as a component of domestic welfare, or that providing payments to foreign firms to subsidise their acquisitions of domestic firms might be politically sensitive.

Additionally, the introduction of acquisition subsidies increases the scope for welfare-reducing subsidy competition. Specifically, we find that for relatively high fixed costs of greenfield FDI, such that unsubsidised acquisition prevailed in the analysis of earlier sections, we now find subsidies being offered that involve a transfer of resources from the country that attracts the investment to the MNC. The size of this transfer is increased by competition from the country that does not attract the MNC. 


\section{Conclusions}

We have developed a model of subsidy competition for an MNC's location in two potential PTA partners, that brings into the analysis the possibility of acquisitions as an alternative to greenfield investment. Our results emphasise the likelihood of socially harmful subsidy competition, hence differing from those previously found in the literature which, focusing exclusively on greenfield investment, generally makes a positive assessment of subsidy competition.

The negative effect of subsidy competition persists, or it is reinforced, in a variety of situations. First, the presence of positive MNC externalities leads to fiercer competition and hence a higher social cost. Second, trade integration reduces the cost of subsidy competition when externalities are absent or low, but further increase harmful competition for high externalities. Third, we show that welfare-reducing subsidy competition occurs even when the process determining the acquisition price incorporates the possibility of subsidies. Finally, the possibility of subsidising acquisition increases the scope for welfare losses associated with subsidy competition.

\section{References}

Aitken, B. and A. Harrison (1999), "Do Domestic Firms Benefit from Direct Foreign Investment? Evidence from Venezuela", American Economic Review, 89, pp. 605-618.

Arnold, J. and B. Javorcik (2007), "Foreign Acquisitions and Plant Performance in Indonesia", World Bank Dicussion Paper 3193.

Barros, P. and L. Cabral (2000), "Competing for Foreign Investment", Review of International Economics, 8 , pp. 360-371.

Bertrand, O. (2005), "On the Effects of Economic Integration on Greenfield Investments and crossborder M\&A location pattern", Journal of Economic Integration, 20, pp. 26-51.

Bjorvatn, K. (2004), "Economic Integration and the Profitability of Cross-border Mergers and Acquisitions", European Economic Review, 48, pp.1211-1226.

Bjorvatn, K. and C. Eckel (2006), "Policy Competitiom for Foreign Direct Investment between Asymmetric Countries", European Economic Review, 50, pp. 1891-1907.

Blomström, M. and A. Kokko (2003), "The Economics of FDI Incentives", NBER Working Paper 9489

Blyde, J., M. Kugler, and E. Stein (2004). "Exporting vs Outsourcing by MNC Subsidiaries: Which Determines FDI Spillovers?", Mimeo.

Calderón, C., N. Loayza and L. Servén (2002), "Greenfield FDI vs. Mergers and Acquisitions: Does the Distinction Matter?", World Bank mimeo.

Charlton, A. (2003), "Incentive Bidding for Mobile Investment: Economic Consequences and Potential Responses", OECD Development Centre Working Paper No. 203 (Formerly Technical Paper No. 203)

Falvey, R. (1998), "Mergers in Open Economies", World Economy, 28, pp. 1061-76. 
Fumagalli, C. (2003), "On the Welfare Effects of Competition for FDI", European Economic Review, 47 , pp. 963-983.

Haaland, J. I. and I. Wooton (1999), "International Competition for Multinational Investments", Scandinavian Journal of Economics, 101, pp. 631-649.

Haufler, A. and I. Wooton (1999), "Tax Competition for Foreign Direct Investment", Journal of Public Economics, 71, pp. 121-139.

Head K. and J. Ries (1997), "International Mergers and Welfare under decentralized competition policy", Canadian Journal of Economics, 30, pp. 1104-23.

Kendall, T. and C. Ryan (2006), "Regional Economic Integration, Mergers and FDI: Welfare and Policy Implications for ASEAN", in Chirathivat, S, Knipping, F, Ryan, C and P.J.J Welfens (eds), EU-ASEAN: Facing Economic Globalisation. Springer-Verlag Heidelberg.

Kind, H.J., K. H. Midelfart-Knarvik and G. Schjelderup (2000), "Competing for Capital in a Lumpy World", Journal of Public Economics, 78, pp. 253-274.

Kugler, M. (2006), "Spillovers from Foreign Direct Investment: Within or Between Industries?", Journal of Development Economics, 80, pp. 444-477.

Long, N.V. and N. Vousden (1995), "The Effects of Trade Liberalisation on Cost-Reducing Horizontal Mergers", Review of International Economics, 3, pp. 141-155.

Ludema, R.D. and I. Wooton (2000), "Economic Geography and the Fiscal Effects of Regional Integration", Journal of International Economics, 52, pp. 331-357.

Mattoo, A., M. Olarreaga and K. Saggi (2004), "Mode of Foreign Entry, Technology Transfer, and FDI Policy", Journal of Development Economics, 75, pp. 95-111.

Norbäck, P.-J. and L. Persson (2008), "Globalization and Profitability of Cross-border Mergers and Acquisitions", Economic Theory, 2008, 35, pp. 241-266.

Oman, C. (2000), "Policy Competition for Foreign Direct Investment", OECD Development Center Studies.

Salant, S. W., S. Switzer and R. J. Reynolds (1983), "Losses from Horizontal Merger: The Effects of an Exogenous Change in Industry Structure on Cournot-Nash Equilibrium", Quarterly Journal of Economics, 98, pp 185-99.

Smarzynska Javorcik, B. (2004), "Does FDI Increase the Productivity of Domestic Firms? In Search of Spillovers Through Backward Linkages", American Economic Review, 94, pp. 605-627.

UNCTAD, Division on Transnational Corporations and Investment (1996), "Incentives and Foreign Direct Investment", Current Studies, Series A, No. 30, New York and Geneva. 


\section{Appendices.}

Long versions of proofs are supplied for referees and editor, shorter versions can be supplied for publication.

\section{Appendix 1: Final stage outputs and prices}

For greenfield FDI in country 1 the outputs are:

$$
\begin{array}{ll}
q_{11}^{G 1}=\frac{a_{1}-2 c+\tau}{4} & q_{21}^{G 1}=\frac{a_{2}-2 c-2 \tau}{4} \\
q_{12}^{G 1}=\frac{a_{1}-2 c-3 \tau}{4} & q_{22}^{G 1}=\frac{a_{2}-2 c+2 \tau}{4} \\
q_{13}^{G 1}=\frac{a_{1}+2 c+\tau}{4} & q_{23}^{G 1}=\frac{a_{2}+2 c-2 \tau}{4}
\end{array}
$$

while for acquisition in 1 they are:

$$
\begin{array}{ll}
q_{11}^{A 1}=0 & q_{21}^{A 1}=0 \\
q_{12}^{A 1}=\frac{a_{1}-2 c-2 \tau}{3} & q_{22}^{A 1}=\frac{a_{2}-2 c+\tau}{3} \\
q_{13}^{A 1}=\frac{a_{1}+c+\tau}{3} & q_{23}^{A 1}=\frac{a_{2}+c-2 \tau}{3}
\end{array}
$$

Outputs under both modes in country 2 can be seen simply by relabelling firms 1 and 2 above. Total outputs and prices in country 1 in the five cases are given by:

$$
\begin{array}{ll}
Q_{1}^{G 1}=\frac{3 a_{1}-2 c-\tau}{4} & P_{1}^{G 1}=\frac{a_{1}+2 c+\tau}{4} \\
Q_{1}^{A 1}=\frac{2 a_{1}-c-\tau}{3} & P_{1}^{A 1}=\frac{a_{1}+c+\tau}{3} \\
Q_{1}^{G 2}=\frac{3 a_{1}-2 c-2 \tau}{4} & P_{1}^{G 2}=\frac{a_{1}+2 c+2 \tau}{4} \\
Q_{1}^{A 2}=\frac{2 a_{1}-c-\tau}{3} & P_{1}^{A 2}=\frac{a_{1}+c+\tau}{3}
\end{array}
$$

with similar expressions for country 2 .

\section{Appendix 2: Subsidy competition and regional welfare}

\section{Existence and unicity of equilibrium}

Lemma 2 (Existence and unicity of the subgame-perfect equilibrium) There exists a unique equilibrium of the three-stage game. According to social and private preferences over investment types, the equilibrium may belong to one of the following categories:

1. Candidate Equilibrium 1: $\left(\chi_{21}^{G G}(2)-\Delta_{12}^{G G}, 0, G 1\right)$

2. Candidate Equilibrium 2: $\left(\Delta_{11}^{A G}, 0, G 1\right)$

3. Candidate Equilibrium 3: $(0,0, G 1)$ 
Proof. We solve for subgame-perfect equilibria of the three-stage game using backward induction. It is assumed throughout that no acquisition subsidies are available and that greenfield subsidies are constrained to be non-negative. To avoid 'ties' in the subsidy game, we have assumed country 1 to be larger than country 2 , in the sense that $a_{1}>a_{2}$. This geographical advantage translates straightforwardly into a more profitable location alternative than locating in country 2 .

Third stage As mentioned in the main text, third stage outputs are not affected by government intervention, because subsidies are lump-sum. Outputs are given by equations (22) and (23) in Appendix 1, and profits equal the sum over countries of squared outputs.

Second stage The MNC will choose an investment type $\theta \in\{G 1, G 2, A 1, A 2\}$ so as to maximise profits inclusive of subsidies. Note that due to our assumption on home market sizes, $A 2$ is always payoff-dominated for the MNC. It is straightforward to write the optimal decision rule:

$$
\theta\left(S_{1}, S_{2}\right)= \begin{cases}A 1 & \text { if } 0 \leq S_{1} \leq \Delta_{11}^{A G} \text { and } 0 \leq S_{2}<\Delta_{12}^{A G} \\ G 1 & \text { if } S_{1}>\Delta_{11}^{A G} \text { and } S_{1}>S_{2}-\Delta_{12}^{G G} \\ G 2 & \text { if } S_{2} \geq \Delta_{12}^{A G} \text { and } S_{1} \leq S_{2}-\Delta_{12}^{G G}\end{cases}
$$

We now distinguish between two cases: when the MNC would prefer greenfield investment without intervention $\left(F<F_{M N C}\right)$, or when it would prefer acquisition $\left(F \geq F_{M N C}\right)$.

First stage $\left(F<F_{M N C}\right)$ Governments maximise national welfare minus subsidy expenditure. Because the presence of a greenfield investor raises consumer surplus, both governments prefer investment at home to abroad, and will pay no subsidies if they expect the MNC to invest abroad. ${ }^{27}$ The MNC prefers greenfield investment to acquisition in the absence of subsidies. Hence we must have three types of candidate equilibria: $(0,0, G 1),\left(S_{1}, 0, G 1\right),\left(0, S_{2}, G 2\right)$.

Consider the candidate equilibrium $(0,0, G 1)$. Governments' willingness to subsidise will equal the welfare gain due to investment at home over investment abroad, i.e. $\chi_{12}^{G G}(1)$ and $\chi_{21}^{G G}(2)$ for governments 1 and 2 respectively. Obviously government 1 will not intervene against a zero subsidy by its rival. Then using Equation (24), equilibrium $(0,0, G 1)$ obtains if government 2 's best-reply to a zero subsidy is a zero subsidy, or:

$$
0>\chi_{21}^{G G}(2)-\Delta_{12}^{G G}
$$

If this inequality holds, then Candidate Equilibrium 3 exists and is the unique subgame-perfect equilibrium.

\footnotetext{
${ }^{27}$ In addition, we assume that in case of a tie, governments offer a subsidy anyway. The widespread popularity of greenfield investment among policy-makers suggests this assumption is realistic.
} 
When this inequality does not hold, subsidy competition occurs. Recall that investment at home is preferred to abroad, but that subsidies enter welfare functions additively and negatively. Therefore, governments' best-reply subsidies must equal:

$$
\begin{aligned}
& S_{1}^{*}\left(S_{2}\right)=\min \left\{S_{2}-\Delta_{12}^{G G}-\epsilon, \chi_{12}^{G G}(1)\right\} \\
& S_{2}^{*}\left(S_{1}\right)=\min \left\{S_{1}+\Delta_{12}^{G G}-\epsilon, \chi_{21}^{G G}(2)\right\}
\end{aligned}
$$

where $\epsilon$ may be arbitrarily small. The exact intersection depends on a comparison of governments'willingness to subsidise. Government 1 receives the investment if the following inequality holds:

$$
\chi_{12}^{G G}(1)>\chi_{21}^{G G}(2)-\Delta_{12}^{G G}
$$

Since we assumed a larger home market for country 1, the latter condition always holds. This proves the existence and unicity of Candidate Equilibrium $1 .{ }^{28}$

First stage $\left(F \geq F_{M N C}\right)$ The MNC prefers acquisition in the absence of intervention. Since incentives only apply to greenfield investment, an equilibrium with acquisition exists if and only if governments' willingness to subsidise falls short of profit differentials. Note that by Equation (24), $\forall S_{1} \in\left[0, \Delta_{11}^{A G}\right], \forall S_{2} \in\left[0, \Delta_{12}^{A G}\right], \theta\left(S_{1}, S_{2}\right)=A 1$. Hence against a subsidy conducive to $A 1$, the maximum willingness to subsidise is given by welfare differentials between $A 1$ and greenfield investment at home. This may be written as :

$$
\begin{aligned}
& \chi_{11}^{G A}(1) \leq \Delta_{11}^{A G} \\
& \chi_{21}^{G A}(2) \leq \Delta_{12}^{A G}
\end{aligned}
$$

This is true in particular if the left-hand-side terms are negative, meaning that $A 1$ is strictly preferred by both governments to all other investment types. More generally, if these inequalities hold, then governments will remain inactive rather than offer subsidies likely to overturn the MNC's location decision. From Equation (24) the equilibrium is: $(0,0, A 1)$. This proves the existence and unicity of Candidate Equilibrium 4.

When Equations (25) and (26) do not hold jointly, we are left with three alternatives. From Equation (24) we know that all remaining alternatives will involve greenfield investment, as at least one government will successfully intervene. Indeed, in each case at least one government will prefer greenfield investment at home by a large enough welfare differential.

Consider first the case where Equation (25) holds and Equation (26) does not hold. Government 2 will consider intervention. We must distinguish between two sub-cases, according to government 1's best-reply to an $S_{2}$ large enough to influence the MNC. In the first sub-case, if $\chi_{12}^{G G}(1) \leq \Delta_{11}^{A G}$, then government 1 never finds it in its interest to intervene against a subsidy conducive to $G 2$. But we already had that government 1 would not intervene against a subsidy conducive to $A 1$. Hence government 1's best-reply strategy is to refrain from intervention (a horizontal flat best-reply schedule at zero). Thus when the above condition holds, the equilibrium must be $\left(0, \Delta_{12}^{A G}, G 2\right)$, independent of 2's behaviour. In the second sub-case, if $\chi_{12}^{G G}(1)>\Delta_{11}^{A G}$,

\footnotetext{
${ }^{28}$ Note that the prevailing equilibrium resembles an asymmetric Bertrand equilibrium, or a second-price auction with complete information and asymmetric valuations.
} 
then intervention from 1 is possible. Again, the game resembles a Bertrand pricing game, but it is made more complicated due to the possibility of acquisition in country 1 . Indeed, government 1's best-reply against a subsidy conducive to $A 1$ is not to intervene; however, its best-reply against a subsidy conducive to $G 2$ is to make a slightly better bid. Hence the discontinuity in government 1's best-reply. Government 2's best-reply against a subsidy conducive to $A 1$ is to compensate for the profit differential. Against a larger subsidy it must make a slightly better bid. Thus governments' best-reply subsidies must equal:

$$
\begin{aligned}
& S_{1}^{*}\left(S_{2}\right)= \begin{cases}0 & \text { if } S_{2}<\Delta_{12}^{A G} \\
\min \left\{S_{2}-\Delta_{12}^{G G}-\epsilon, \chi_{12}^{G G}(1)\right\} & \text { if } S_{2} \geq \Delta_{12}^{A G}\end{cases} \\
& S_{2}^{*}\left(S_{1}\right)= \begin{cases}\Delta_{12}^{A G} & \text { if } S_{1}<\Delta_{11}^{A G} \\
\min \left\{S_{1}+\Delta_{12}^{G G}-\epsilon, \chi_{21}^{G G}(2)\right\} & \text { if } S_{1} \geq \Delta_{11}^{A G}\end{cases}
\end{aligned}
$$

where $\epsilon$ may be arbitrarily small. Again, the outcome of the game hinges on the comparison between governments' willingness to subsidise. Since the inequality in Equation (5) always holds, Country 1 hosts FDI. Again, the unique subgame-perfect equilibrium is Equilibrium 1.

Consider now the second of our three cases, where Equation (25) does not hold and Equation (26) holds. This means that government 1 prefers greenfield investment at home to $A 1$ by some margin, unlike government 2. Government 1 will consider intervention. We must distinguish between two sub-cases, according to government 2's best-reply against a subsidy conducive to $G 1$. In the first sub-case, if $\chi_{21}^{G G}(2) \leq \Delta_{12}^{A G}$, then government 2 never finds it in its interest to intervene against a subsidy conducive to $G 1$. But we already had that government 2 would not intervene against a subsidy conducive to $A 1$. Hence government 2's best-reply strategy is to refrain from intervention (a flat vertical best-reply schedule). Thus when the above condition holds, the equilibrium must be $\left(\Delta_{11}^{A G}, 0, G 1\right)$, independent of 2's behaviour. This proves the existence and unicity of Candidate Equilibrium 2. In the second sub-case, if $\chi_{21}^{G G}(2)>\Delta_{12}^{A G}$, then intervention from 2 is possible. Again, the game resembles a Bertrand pricing game, but it is made more complicated due to the possibility of acquisition in country 1. Indeed, in this sub-case, government 2's best-reply against a subsidy conducive to $A 1$ is not to intervene, whereas its best-reply against a subsidy conducive to $G 2$ is to make a slightly better bid. Hence the discontinuity in government 2's best-reply schedule. Government 1's best-reply against a subsidy conducive to $A 1$ is to simply compensate for the profit differential. Against a larger subsidy it need make a slightly better bid. Thus governments' best-reply subsidies must equal:

$$
\begin{aligned}
& S_{1}^{*}\left(S_{2}\right)= \begin{cases}\Delta_{11}^{A G} & \text { if } S_{2}<\Delta_{12}^{A G} \\
\min \left\{S_{2}-\Delta_{12}^{G G}-\epsilon, \chi_{12}^{G G}(1)\right\} & \text { if } S_{2} \geq \Delta_{12}^{A G}\end{cases} \\
& S_{2}^{*}\left(S_{1}\right)= \begin{cases}0 & \text { if } S_{1} \leq \Delta_{11}^{A G} \\
\min \left\{S_{1}+\Delta_{12}^{G G}-\epsilon, \chi_{12}^{G G}(2)\right\} & \text { if } S_{1}>\Delta_{11}^{A G}\end{cases}
\end{aligned}
$$

where $\epsilon$ may be arbitrarily small. The outcome of the subsidy game will be Equilibrium 1 .

In the third and last case, Equations (25) and (26) both hold, implying that governments 
prefer greenfield investment at home rather than $A 1$ and will intervene. It should now be clear that governments' best-reply subsidies will be given by:

$$
\begin{aligned}
& S_{1}^{*}\left(S_{2}\right)= \begin{cases}\Delta_{11}^{A G} & \text { if } S_{2}<\Delta_{12}^{A G} \\
\min \left\{S_{2}-\Delta_{12}^{G G}-\epsilon, \chi_{12}^{G G}(1)\right\} & \text { if } S_{2} \geq \Delta_{12}^{A G}\end{cases} \\
& S_{2}^{*}\left(S_{1}\right)= \begin{cases}\Delta_{11}^{A G} & \text { if } S_{1} \leq \Delta_{11}^{A G} \\
\min \left\{S_{1}+\Delta_{12}^{G G}-\epsilon, \chi_{21}^{G G}(2)\right\} & \text { if } S_{1}>\Delta_{11}^{A G}\end{cases}
\end{aligned}
$$

Once again, Equation (5) holds and Equilibrium 1 prevails.

To summarise, the exhaustive set of conditions below determines which equilibrium prevails:

1. $F<F_{M N C}$

(a) If $\chi_{21}^{G G}(2)<\Delta_{12}^{G G}$ Equilibrium : $(0,0, G 1)$

(b) If $\chi_{21}^{G G}(2) \geq \Delta_{12}^{G G}$

i. If $\chi_{12}^{G G}(1)+\Delta_{12}^{G G}>\chi_{21}^{G G}(2)$ Equilibrium: $\left(\chi_{21}^{G G}(2)-\Delta_{12}^{G G}, 0, G 1\right)$

ii. If $\chi_{12}^{G G}(1)+\Delta_{12}^{G G} \leq \chi_{21}^{G G}(2)$ Equilibrium: $\left(0, \chi_{12}^{G G}(1)+\Delta_{12}^{G G}, G 2\right)$

2. $F \geq F_{M N C}$

(a) If $\chi_{11}^{G A}(1) \leq \Delta_{11}^{A G}$ and $\chi_{21}^{G A}(2) \leq \Delta_{12}^{A G}$ Equilibrium: $(0,0, A 1)$

(b) If $\chi_{11}^{G A}(1) \leq \Delta_{11}^{A G}$ and $\chi_{21}^{G A}(2)>\Delta_{12}^{A G}$

i. If $\chi_{12}^{G G}(1) \leq \Delta_{11}^{A G}$ Equilibrium : $\left(0, \Delta_{12}^{A G}, G 2\right)$

ii. If $\chi_{12}^{G G}(1)>\Delta_{11}^{A G}$

A. If $\chi_{12}^{G G}(1)+\Delta_{12}^{G G}>\chi_{21}^{G G}(2)$ Equilibrium: $\left(\chi_{21}^{G G}(2)-\Delta_{12}^{G G}, 0, G 1\right)$

B. If $\chi_{12}^{G G}(1)+\Delta_{12}^{G G} \leq \chi_{21}^{G G}(2)$ Equilibrium: $\left(0, \chi_{12}^{G G}(1)+\Delta_{12}^{G G}, G 2\right)$

(c) If $\chi_{11}^{G A}(1)>\Delta_{11}^{A G}$ and $\chi_{21}^{G A}(2) \leq \Delta_{12}^{A G}$

i. If $\chi_{21}^{G G}(2)<\Delta_{12}^{A G}$ Equilibrium: $\left(\Delta_{11}^{A G}, 0, G 1\right)$

ii. If $\chi_{21}^{G G}(2) \geq \Delta_{12}^{A G}$

A. If $\chi_{12}^{G G}(1)+\Delta_{12}^{G G}>\chi_{21}^{G G}(2)$ Equilibrium: $\left(\chi_{21}^{G G}(2)-\Delta_{12}^{G G}, 0, G 1\right)$

B. If $\chi_{12}^{G G}(1)+\Delta_{12}^{G G} \leq \chi_{21}^{G G}(2)$ Equilibrium: $\left(0, \chi_{12}^{G G}(1)+\Delta_{12}^{G G}, G 2\right)$

(d) If $\chi_{11}^{G A}(1)>\Delta_{11}^{A G}$ and $\chi_{21}^{G A}(2)>\Delta_{12}^{A G}$

i. If $\chi_{12}^{G G}(1)+\Delta_{12}^{G G}>\chi_{21}^{G G}(2)$ Equilibrium: $\left(\chi_{21}^{G G}(2)-\Delta_{12}^{G G}, 0, G 1\right)$

ii. If $\chi_{12}^{G G}(1)+\Delta_{12}^{G G} \leq \chi_{21}^{G G}(2)$ Equilibrium: $\left(0, \chi_{12}^{G G}(1)+\Delta_{12}^{G G}, G 2\right)$

It is easy to see that Conditions 1.b.i., 2.b.ii.A, 2.c.ii.A and 2.d.ii.A are identical and lead to Candidate Equilibrium 1. Condition 2.c.i. leads to Candidate Equilibrium 2. Condition 1.a. leads to Candidate Equilibrium 3. Condition 2.a. The fourth condition leads to Candidate Equilibrium 4. Because of country 1's assumed geographic advantage, none of the other conditions is ever met. 


\section{The outcome of the subsidy game (proof of Lemma 3)}

A critical variable to determine the prevailing equilibrium for given social and private preferences over investment types is the fixed cost of greenfield investment.

Since this variable is exogenous in our model, and since it affects the MNC's decision over modes, we will find various outcomes over the interval of all possible fixed costs. We introduce the following useful notation:

$$
\begin{aligned}
F_{M N C} & =\Delta_{11}^{G A}+F \\
F_{1} & =\chi_{11}^{G A}(1)+\Delta_{11}^{G A}+F \\
F_{1}^{\prime} & =\chi_{12}^{G G}(1)+\Delta_{11}^{G A}+F \\
F_{2} & =\chi_{21}^{G A}(2)+\Delta_{21}^{G A}+F \\
F_{2}^{\prime} & =\chi_{21}^{G G}(2)+\Delta_{21}^{G A}+F
\end{aligned}
$$

The first threshold denotes the level of fixed costs over which investment by acquisition is more profitable than greenfield investment without subsidies.

The following four thresholds denote levels of fixed costs over which each government will find it too costly to subsidise greenfield investment at home. There are two such thresholds for each government as the alternative to greenfield investment at home may be either acquisition or greenfield investment abroad.

The analytic expressions for these thresholds, which will prove useful in the calculations below, are given by:

$$
\begin{aligned}
F_{M N C} & =\frac{1}{144}\left(9\left(a_{1}\right)^{2}+9\left(a_{2}\right)^{2}+72 c^{2}+45 \tau^{2}-28 a_{1} c-28 a_{2} c+18 a_{1} \tau-36 a_{2} \tau+28 c \tau\right) \\
F_{1} & =\frac{1}{288}\left(21\left(a_{1}\right)^{2}+4\left(a_{2}\right)^{2}+244 c^{2}+13 \tau^{2}-108 a_{1} c-64 a_{2} c+18 a_{1} \tau-16 a_{2} \tau+68 c \tau\right) \\
F_{1}^{\prime} & =\frac{1}{288}\left(18\left(a_{1}\right)^{2}+18\left(a_{2}\right)^{2}+144 c^{2}-81 \tau^{2}-56 a_{1} c-56 a_{2} c+54 a_{1} \tau-36 a_{2} \tau+20 c \tau\right) \\
F_{2} & =\frac{1}{288}\left(4\left(a_{1}\right)^{2}+21\left(a_{2}\right)^{2}+52 c^{2}+13 \tau^{2}-44 a_{2} c-16 a_{1} \tau+18 a_{2} \tau+4 c \tau\right) \\
F_{2}^{\prime} & =\frac{1}{288}\left(18\left(a_{1}\right)^{2}+18\left(a_{2}\right)^{2}+144 c^{2}-81 \tau^{2}-56 a_{1} c-56 a_{2} c+36 a_{1} \tau-54 a_{2} \tau+20 c \tau\right)
\end{aligned}
$$

We are now in a position to show which equilibrium prevails for a given value of the fixed cost.

Using Condition 1 and the set of conditions from the previous subsection, we can find the unique equilibrium of the subsidy game for each level of fixed cost.

1. When $F<F_{M N C}$

- If $F_{1}^{\prime}>F_{2}^{\prime}$, Equilibrium: $\left(\chi_{21}^{G G}(2)-\Delta_{12}^{G G}, 0, G 1\right)$

- If $F_{1}^{\prime} \leq F_{2}^{\prime}$ Equilibrium: $\left(0, \chi_{12}^{G G}(1)+\Delta_{12}^{G G}, G 2\right)$ 
2. When $F \geq F_{M N C}$

(a) When $F \geq F_{1}$ and $F \geq F_{2}$, Equilibrium: $(0,0, A 1)$

(b) When $F \geq F_{1}$ and $F<F_{2}$ :

- When $F \geq F_{1}^{\prime}$ Equilibrium: $\left(0, \Delta_{12}^{A G}, G 2\right)$

- When $F<F_{1}^{\prime}$ then:

- If $F_{1}^{\prime}>F_{2}^{\prime}$, Equilibrium: $\left(\chi_{21}^{G G}(2)-\Delta_{12}^{G G}, 0, G 1\right)$

- If $F_{1}^{\prime} \leq F_{2}^{\prime}$ Equilibrium: $\left(0, \chi_{12}^{G G}(1)+\Delta_{12}^{G G}, G 2\right)$

(c) When $F<F_{1}$ and $F \geq F_{2}$ :

- When $F>F_{2}^{\prime}$, Equilibrium: $\left(\Delta_{11}^{A G}, 0, G 1\right)$

- When $F \leq F_{2}^{\prime}$ :

- If $F_{1}^{\prime}>F_{2}^{\prime}$, Equilibrium: $\left(\chi_{21}^{G G}(2)-\Delta_{12}^{G G}, 0, G 1\right)$

- If $F_{1}^{\prime} \leq F_{2}^{\prime}$ Equilibrium: $\left(0, \chi_{12}^{G G}(1)+\Delta_{12}^{G G}, G 2\right)$

(d) When $F<F_{1}$ and $F<F_{2}$ :

- If $F_{1}^{\prime}>F_{2}^{\prime}$, Equilibrium: $\left(\chi_{21}^{G G}(2)-\Delta_{12}^{G G}, 0, G 1\right)$

- If $F_{1}^{\prime} \leq F_{2}^{\prime}$ Equilibrium: $\left(0, \chi_{12}^{G G}(1)+\Delta_{12}^{G G}, G 2\right)$

Using this set of conditions, we can rank fixed cost thresholds in order to give a complete characterisation of the equilibrium. This leads to the following Lemma:

Lemma 3 Fixed costs thresholds are ranked as follows:

$$
F_{1}^{\prime}>F_{2}^{\prime}>\max \left\{F_{1}, F_{2}\right\}>\min \left\{F_{1}, F_{2}\right\}>F_{M N C}
$$

Proof. Tedious but straightforward calculations show that:

$$
\begin{aligned}
& F_{2}-F_{M N C}=\frac{1}{32}\left(14 a_{2}-8 a_{1}-4 c-19 \tau\right) \\
& F_{1}-F_{2}=\frac{1}{288}\left(17\left(a_{1}\right)^{2}-17\left(a_{2}\right)^{2}-a_{1}(108 c-34 \tau)-2 a_{2}(10 c+17 \tau)+64 c(3 c+\tau)\right)
\end{aligned}
$$

The first expression is positive by Condition 1, which states that country 1's geographical advantage and the tariff level are low enough for subsidy competition to be possible.

The sign of the expression in Equation (31) is uncertain: the ranking between these two thresholds depends on production costs and market sizes. For sufficiently similar countries the right-hand-side of Equation (31) is negative and $F_{2}$ is the relevant threshold. For sufficiently different country sizes, the sign of this expression depends on production costs. Consider the highest size difference consistent with Condition 1 , that is $a_{1}=\frac{7}{4} a_{2}-\frac{c}{2}-\frac{19}{8} \tau$. In this case $F_{1}-F_{2}$ is positive for high enough production costs. To see this, take the maximum value of $c$ consistent with positive Cournot outputs, that is $c=\frac{a_{2}}{2}-\tau$. Otherwise, when production costs are low enough, this expression is negative. 
Moreover, note that:

$$
\begin{aligned}
& F_{2}^{\prime}-F_{1}=\frac{1}{288}\left(-3\left(a_{1}\right)^{2}+14\left(a_{2}\right)^{2}+52 a_{1} c+8 a_{2} c-100 c^{2}-54 a_{1} \tau+70 a_{2} \tau-48 c \tau-94 \tau^{2}\right) \\
& F_{1}^{\prime}-F_{2}=\frac{1}{288}\left(14\left(a_{1}\right)^{2}-3\left(a_{2}\right)^{2}-56 a_{1} c+70 a_{1} \tau-12 a_{2} c-54 a_{2} \tau+92 c^{2}+16 c \tau-94 \tau^{2}\right) \\
& F_{1}^{\prime}-F_{2}^{\prime}=\frac{5}{16}\left(a_{1}-a_{2}\right) \tau
\end{aligned}
$$

In Equation (32) it can be seen that the right-hand side is positive for zero and maximum production costs. Since this is a bell-shaped function of $c$, it must be positive over the relevant cost interval. In Equation (33) the right-hand-side is a U-shaped function of $c$ but it can be shown that it takes a positive value at its unique minimum. Finally Equation (34) is clearly positive since we labelled countries 1 and 2 so as to have $a_{1}>a_{2}$. Therefore the sign of the difference between $F_{1}$ and $F_{2}$ does not matter.

\section{Appendix 3: Welfare Analysis with Positive Externalities from FDI}

Again we proceed in two steps, first characterising the equilibrium outcome, and second evaluating the welfare change with respect to no intervention.

Our characterisation is summarised in the following Lemma:

Lemma 4 There exists a threshold $\bar{\phi}$ such that when the spillover parameter exceeds that threshold, the prevailing equilibrium is as follows:

- if $F<F_{2}$, then Equilibrium 1 prevails;

- if $F \geq F_{2}$, then Equilibrium 2 obtains.

Proof. In order to characterise the equilibrium for every possible value of the fixed cost $F$ we need first to check how the ranking in Equation (29) is affected by the existence of positive externalities. The same calculations as in the previous Appendix yield:

$$
\begin{aligned}
F_{2}-F_{M N C} & =\frac{1}{32}\left(14 a_{2}-8 a_{1}-4 c-19 \tau\right)+\frac{1}{4}\left(a_{1}+a_{2}+4 c-\tau\right) \\
F_{1}-F_{2} & =\frac{1}{288}\left(17\left(a_{1}\right)^{2}-17\left(a_{2}\right)^{2}-a_{1}(108 c-34 \tau)-2 a_{2}(10 c+17 \tau)+64 c(3 c+\tau)\right) \\
& -\frac{1}{6} \phi\left(a_{1}+a_{2}+4 c-\tau\right)
\end{aligned}
$$

The first expression is still positive. The expression in (36) must be negative for all values of the production costs when positive externalities are significant enough. Specifically, the threshold 
value of $\phi$ is equal to

$$
\bar{\phi}=\frac{48\left(a_{1}+a_{2}+4 c-\tau\right)}{17\left(a_{1}\right)^{2}-17\left(a_{2}\right)^{2}-a_{1}(108 c-34 \tau)-2 a_{2}(10 c+17 \tau)+64 c(3 c+\tau)}
$$

Further, note that:

$$
\begin{aligned}
F_{2}^{\prime}-F_{1} & =\frac{1}{288}\left(-3\left(a_{1}\right)^{2}+14\left(a_{2}\right)^{2}+52 a_{1} c+8 a_{2} c-100 c^{2}-54 a_{1} \tau+70 a_{2} \tau-48 c \tau-94 \tau^{2}\right) \\
& +\frac{1}{6} \phi\left(a_{1}+a_{2}+4 c-\tau\right) \\
F_{1}^{\prime}-F_{2} & =\frac{1}{288}\left(14\left(a_{1}\right)^{2}-3\left(a_{2}\right)^{2}-56 a_{1} c+70 a_{1} \tau-12 a_{2} c-54 a_{2} \tau+92 c^{2}+16 c \tau-94 \tau^{2}\right) \\
F_{1}^{\prime}-F_{2}^{\prime} & =\frac{5}{16}\left(a_{1}-a_{2}\right) \tau
\end{aligned}
$$

The expression in (38) remains positive, while the last two equations are unchanged. Therefore the ranking between these thresholds is again given by:

$$
F_{1}^{\prime}>F_{2}^{\prime}>\max \left\{F_{1}, F_{2}\right\}>\min \left\{F_{1}, F_{2}\right\}>F_{M N C}
$$

where $\max \left\{F_{1}, F_{2}\right\}=F_{2}$ if and only if $\phi \geq \bar{\phi}$. This completes the proof of Lemma 4 .

\section{Proof of Proposition 3}

We use the same reasoning as in the proof of Proposition 2.

By Lemma 4, Equilibrium 1 obtains when $F<F_{M N C}$ and by the same logic as before, subsidy competition leads to a welfare loss. As proved earlier, subsidisation does not affect the mode of entry, nor does it affect the extent of positive externalities, while subsidy expenditure reduces welfare.

By the same Lemma, when $F_{M N C} \leq F<\max \left\{F_{1}, F_{2}\right\}$, Equilibrium 1 obtains again, and by Equations (38), (39) and (40) we still have that:

$$
\chi_{11}^{G A}(1)+\chi_{11}^{G A}(2)-\left(\chi_{21}^{G G}(2)-\Delta_{12}^{G G}\right)<0
$$

which is equal to the regional welfare differential between subsidy competition at Equilibrium 1 and no intervention.

Finally, by the same Lemma, Equilibrium 4 obtains when $F \geq \max \left\{F_{1}, F_{2}\right\}$ which implies zero subsidies and no welfare loss.

Rewriting the expression for $F_{2}$ in the case of spillovers and differentiating it with respect to $\phi$ yields: 


$$
\begin{aligned}
F_{2} & =\frac{1}{288}\left(4\left(a_{1}\right)^{2}+21\left(a_{2}\right)^{2}+52 c^{2}+13 \tau^{2}-44 a_{2} c-16 a_{1} \tau+18 a_{2} \tau+4 c \tau\right)+\frac{\phi}{4}\left(a_{1}+4 c-\tau\right) \\
\frac{\partial F_{2}}{\partial \phi} & =\frac{1}{4}\left(a_{1}+4 c-\tau\right)
\end{aligned}
$$

where the latter derivative is evidently positive. This proves the second part of the Proposition.

Finally in the presence of positive externalities Equation (6) can be rewritten as:

$$
\chi_{21}^{G G}(2)-\Delta_{12}^{G G}=\tau \frac{1}{32}\left(14 a_{2}-8 a_{1}-4 c-19 \tau\right)+\frac{1}{32} \phi\left(8 a_{1}+8 a_{2}+32 c-8 \tau\right)
$$

Equilibrium 1 subsidies equal $\chi_{21}^{G G}(2)-\Delta_{12}^{G G}$, which increases in $\phi$, implying even greater subsidisation than without positive externalities. 